\title{
INVESTIGANDO O CARÁTER SITUADO DO CONHECIMENTO: REFLEXÕES SOBRE EPISTEMOLOGIAS FEMINISTAS E EDUCAÇÃO CIENTÍFICA E TECNOLÓGICA
}

The situated knowledge aspects: reflections about feminist epistemologies and scientific and technological education

Carla Giovana Cabral*

\section{Resumo}

O afastamento histórico entre razão e emoção apartou os sujeitos feminino e masculino, construindo uma noção de objetividade que também isola em campos opostos a racionalidade científica e o compromisso social e emocional. Essa dicotomia tem alheado o gênero da construção do conhecimento científico, no que também colabora para um entendimento pouco crítico da relação entre a ciência, a tecnologia e a sociedade, tendendo a uma compreensão ingênua de que essas atividades são realizadas por um sujeito pretensamente neutro. Epistemologias feministas lançam olhares distintos sobre esses e outros aspectos, nem sempre se conciliam, há conflitos, semelhanças. Tentamos, a partir de alguns desses olhares, empreender uma análise a caminho de um conhecimento que é produto da interação entre sujeito e objeto do conhecimento - e ponto de partida para a possibilidade de uma dialogicidade. Em nossa leitura também verificamos algumas implicações da visão tradicional de ciência e tecnologia sobre a noção de objetividade e refletimos a respeito da mulher como um sujeito histórico e socialmente situado e a contribuição desse

* Mestre em Literatura e doutorado em Educação Científica e Tecnológica pela Universidade Federal de Santa Catarina (UFSC). Pesquisadora no Núcleo de Estudos e Pesquisas em Educação Tecnológica (Nepet/UFSC). (carla@ctc.ufsc.br) 
olhar para uma educação transformadora. Afinal, por que as decisões que levam em conta o caráter social e categorias como o gênero devem ser tomadas necessariamente como irracionais e não objetivas?

Palavras-chave: epistemologia feminista; gênero, ciência e tecnologia; educação tecnológica.

\section{Abstract}

The historical removal between reason and emotion separated the feminine subjects and masculine, building an objectivity notion that also isolates in opposed fields the scientific rationality and the social and emotional commitment. That dichotomy has been alienating the gender of the construction of the scientific knowledge, in what it also collaborates for an understanding little critic of the relationship among the science, the technology and the society, tending to a naive understanding that those activities are accomplished supposedly by a subject neutral. Feminists epistemologies launch different glances on those and other aspects, not always they reconcile, there are conflicts, likeness. We try, starting from some of those glances, to undertake an analysis on the way to a knowledge that is product of the interaction between subject and object of the knowledge - and starting point for the possibility of a dialogue. In our reading we also verify some implications of the traditional vision of science and technology about the objectivity notion and we contemplate regarding the woman as a subject historical and socially located and the contribution of that glance for an transform education. After all, why the decisions that take into account the social character and categories as the gender should necessarily be taken how irrational and don't you aim at?

Keywords: feminist epistemology, gender, science and technology, technology education. 
Quando o demiurgo do Timeo, de Platão, cria as almas, concedelhes uma estrela, que se encarnará em homem. O caminho para tal "privilégio" é a dominação de paixões e emoções e uma vida racional e justa. Desviar-se desse caminho resulta numa espécie de "castigo". Em vez de se reencarnar em homens, as almas que se rendem às paixões voltam à terra como mulheres.

Tão antiga história, tão presente filosofia a suscitar questões sobre o afastamento entre razão e emoção, entre pensar e sentir, alimentando o apartamento dos sujeitos masculino e feminino, construindo uma noção de objetividade que isola em campos opostos a racionalidade científica e o compromisso social e emocional.

Tão comum a dicotomia homem/mulher ainda é, entretanto, dualidade proveitosa para investir em reflexões que relevem o gênero num território de certa forma hostil e pouco acostumado à sua presença, como o é o da ciência e da tecnologia.

Discutir gênero na ciência e na tecnologia é defrontar-se com modos diferentes, às vezes até mesmo pouco compatíveis, de lançar o olhar da epistemologia feminista para uma análise crítica que procure encontrar o conhecimento científico como produto da inter-relação entre sujeito e objeto. Trata-se de uma opção epistemológica e creio ser importante perguntar: por que as decisões que levam em conta o caráter social devem ser tomadas necessariamente como irracionais e não objetivas?

Neste ensaio nós refletimos de forma introdutória sobre o lugar do sujeito feminino na ciência e na tecnologia por meio de uma breve análise crítica das epistemologias feministas e algumas de suas implicações sobre a noção de objetividade.

\section{CENÁRIOS}

São vários os espaços nos quais os estudos sobre ciência, tecnologia e gênero desempenham hoje seu papel. Em uma certa medida, encontraram berço na consciência das mulheres de sua diferença e em 
posicionamentos políticos inerentes ao próprio movimento feminista, como analisam Pérez Sedeño e Gonzáles García ${ }^{1}$.

Por que tão poucas mulheres na ciência e na tecnologia? Essa foi uma questão inaugural de pesquisas que buscam revelar a diferença, no sentido de inferioridade em relação aos homens no mesmo espaço de atuação. Erguem-se, aqui, relações e conflitos entre ciência, tecnologia, gênero e poder. Discutem-se, também, as barreiras que acabam concedendo ao sujeito feminino um estatuto epistêmico inferior. Recuperar historicamente as mulheres na ciência e na tecnologia, refletir sobre a exclusão a que são submetidas e realizar estudos empíricos são alguns exemplos de pesquisas histórico-sociológicas ${ }^{2}$. Há também esforços para trabalhar questões no campo pedagógico, renovando currículos e motivando meninas e mulheres a aprenderem ciências.

Num outro sentido, mas ainda com o objetivo de oposição ao sexismo e ao androcentrismo, releva-se a componente política do feminismo, procurando incorporar o gênero como variável relevante em suas análises críticas da cultura técnico-científica. De um lado, a discussão sobre o efeito da essência feminina sobre guerras e a favor de movimentos antiarmamentistas e ecológicos; de outro, a verificação de que o empreendimento científico era muito sexista, pois erigido sobre valores de dominação e controle tipicamente masculinos.

1 GONZÁlES GARCÍA, M., PÉREZ SEDEÑO, E. “Ciencia, Tecnología y Género”, in: Revista Iberoamericana de Ciencia, Tecnología, Sociedad y Innovación, $n .2$. Madrid: OEI, enero- abril de 2002. p. 1.

2 Exemplos de trabalhos nesta linha são: KELLER, E F. A Feeling for the Organism: The Life and Work of Barbara McClintock. New York: W.H. Fremann, 1983. LOPES, M. M. Gênero, Ciências, História. Revista do Núcleo de Estudos de Gênero Pagu. UNICAMP, 2000. SHIEBINGER, L. O Feminismo mudou a ciência? São Paulo: Universidade do Sagrado Coração. 2001. PERES SEDEÑO, E. "¿El poder de una ilusión?: Ciencia, Género y Feminismo”. In: VIEJA, M. T. L.. (Ed.) Feminismo: del pasado al presente. Salamanca: Universidad de Salamaca, 2000. "Insitucionalización de la Ciencia - valores epistémicos y contextuales: un caso ejemplar". Revista do Núcleo de Estudos de Gênero Pagu. Campinas: UNICAMP, 2000. 
Outra pergunta foi fundamental para que se passasse das questões da mulher na ciência para as da ciência no feminismo ${ }^{3}$, em outras palavras, os estudos sociais das ciências e os estudos feministas sobre a ciênciat. Quais as conseqüências da exclusão da mulher para os conteúdos e as práticas científico-tecnológicas?

Outras questões se seguem e vale a pena conhecê-las como forma de mapear o percurso desses estudos e seus cenários contemporâneos, e cabe repetir uma vez mais heterogêneos. São elas: (1) poderiam os estudos sobre a vida das mulheres revelar aspectos de gênero presentes no conteúdo e nos métodos das ciências? Diferenças localizadas no cérebro ou provocadas por hormônios limitariam a aptidão das mulheres para atividades científicas? Características culturais especificamente femininas favoreceriam as mulheres no exercício da atividade científica? Seria necessário preparar e educar as meninas para facilitar seu acesso a essas atividades? A entrada massiva de mulheres na ciência contribuiria para a superação de "vieses androcêntricos contidos na prática científica? Existiria um estilo feminino (ou feminista) de fazer ciência? Até que ponto as mulheres desenvolvem e seguem abordagens não padronizadas ou são inovadoras na metodologia que utilizam? Seria possível falar em "ciência feminista"?5

Preste-se atenção ao significado que evoca cada pergunta linhas atrás, suas palavras, o que perguntam e o que já estão afirmando ao perguntar.

E quais foram as respostas? Citeli, numa clara apreciação dos estudos da área em língua inglesa, afirma que representativas pesquisadoras, já na década de 80 , responderam que não à maioria delas. Nesse mesmo período, os estudos sobre a exclusão e a invisibilidade das mulheres nas ciências começam a ser vistos como "um assunto de relevância limitada". Uma década depois, fala-se numa certa "baixa prioridade" das feministas ao tema. Segundo a análise de Citeli, as oportunidades para as mulheres na ciência, notadamente para as americanas, aumentaram e outras barreiras, como a da raça, são atualmente mais evidentes.

3 GONZÁLES GARCÍA, M., PÉREZ SEDEÑO, E. Idem, p. 2.

4 CITELI, M.T. "Mulheres nas Ciências: mapeando campos de estudo", in: Revista do Núcleo de Estudos de Gênero Pagu .op. cit, p. 44.

5 Idem, p. 42 
Estudos recentes procuram diagnosticar a situação das mulheres na ciência e na tecnologia. Lona Schiebinger ${ }^{6}$ aponta um aumento no número de mulheres a dirigir agências governamentais, chefiar departamentos e manter cadeiras acadêmicas de prestígio. Foi uma situação que, segundo ela, levou o governo dos Estados Unidos a publicar um relatório sobre a posição das mulheres na ciência. Em O Feminismo Mudou a Ciência?, Schiebinger mostra estatísticas sobre a territorialidade em relação a disciplinas científicas e por etnia naquele país.

Estudos realizados na América Latina ${ }^{7}$ alertam para a ausência de estatísticas diferenciadas por sexo, ao contrário de países desenvolvidos. Uma das ações nesse sentido é o diagnóstico da situação, buscando indicadores, desde a análise etária e com relação ao sexo, até níveis hierárquicos e acesso a bolsas, entre outros.

Esse estudo revelou que, no Brasil, a posição das mulheres líderes, por idade e número total de investigadores, resulta, em todas as faixas etárias, em menos da metade, exceto as mais jovens. Outro dado é que a única área em que as mulheres são maioria é a das Ciências Humanas. Em Ciências Agrárias, Engenharias e Exatas o predomínio é masculino. Os autores concluíram que, no Brasil e na Argentina, há um ingresso massivo de mulheres e que as barreiras se manifestam para que alcancem níveis intermediários altos na carreira científica e tecnológica.

Em virtude da discriminação territorial, se relega às mulheres certas áreas da atividade científica, áreas marcadas pelo sexo, tais como computar dados astronômicos, ou classificar e catalogar em história natural. Isso traduz-se, entre outras coisas, em dizer que determinadas carreiras são mais "femininas" que outras e que certos trabalhos, "feminilizados", adquirem menos valor que outros.

6 SCHIEBNGER, L. O feminismo mudou a ciência. op. cit.

7 KOCHEN, Silvia, FRANCHI, Ana, MAFFÍA, Diana, ATRIO, Jorge. "Situación de las Mujeres en el Sector Científico-Tecnológico en América Latina”. In: PÉREZ SEDEÑO, E. (Editora) Las Mujeres en el Sistema de Ciencia y Tecnología: estudios de caso. Cuadernos de Iberoamerica. Madrid: OEI, 2001, p. 19-39. 
Também existe a discriminação hierárquica, onde mulheres cientistas capazes e brilhantes são mantidas nos níveis inferiores da escala da comunidade ou topam com um teto de cristal, que não podem ultrapassar em sua profissão. ${ }^{8}$

O olhar com que se lê e a partir do qual se trava discussões acerca de temas como esse ou de resultados de pesquisa assim exige o depreender de posturas epistemológicas, que têm provocado interessantes debates no interior do pensamento feminista e nos estudos da ciência de uma maneira geral $^{9}$. O debate entre realistas sociais e pós-modernas, por exemplo, produz tensões. Algumas dessas tensões e a tentativa de buscar uma opção teórica na epistemologia feminista, que se aproxime ou se encontre com um conceito de conhecimento científico e tecnológico baseado na interrelação crítica entre sujeito e objeto, é o que vamos procurar fazer a partir de agora. Estamos cientes da amplitude da discussão e certamente não esgotaremos o assunto, mas pontuaremos o que julgo importante para uma introdução ao tema.

\section{EPISTEMOLOGIAS FEMINISTAS}

É possível falar em epistemologia feminista? As questões que suscitam já não se situariam no campo mesmo da epistemologia?

É pertinente flexionar em número, mas muito provavelmente não em gênero, a epistemologia feminista. Seu corpus é heterogêneo em posturas, mas de uma forma geral defende uma teoria do conhecimento que não despreze o contexto social do sujeito cognoscente. Nesse sentido, o sujeito feminino é um sujeito situado no conhecimento. Quais as implicações disso para o conceito de objetividade na ciência? Quais as conexões entre conhecimento e poder?

As epistemologias feministas abarcam análises que compreendem tanto problemas epistemológicos da perspectiva feminista quanto as que defendem a existência de formas de conhecimento femininas ou ainda uma

8 GONZÁLES GARCÍA, M., PÉREZ SEDEÑO, E. op. cit. p. 7-8.

9 Idem, p. 2. 
teoria do conhecimento ou ciência feminista. Suas abordagens passam pelo: (1) empirismo ingênuo, (2) o enfoque psicodinâmico, (3) a teoria feminista do ponto de vista, (4) o empirismo feminista contextual e (5) as epistemologias pós-modernas.

Sandra Harding ${ }^{10}$ descreve o empirismo ingênuo como uma espistemologia feminista que vê as tendências sexistas e androcêntricas na ciência como fruto do mau emprego do método científico clássico, cuja aplicação correta levaria à 'boa ciência'.

Uma das críticas feitas por Harding ${ }^{11}$ a essa visão é que suas praticantes estão por demais preocupadas com as regras e os princípios da ciência e que o discurso de 'má ciência' e um maior cuidado com a coleta de dados não resultaria propriamente numa epistemologia. Penso, além disso, que ao adotar o método cientifico para eliminar tendências sexistas e androcêntricas surge um problema espistemológico e uma contradição em relação ao próprio feminismo.

A base do método científico é a lógica e a experiência. É um método indutivo para descobrir leis ou fenômenos ${ }^{12}$, que considera a ciência como um empreendimento autônomo, objetivo, neutro e baseado em explicações de um código de racionalidade alheio a qualquer tipo de interferência externa. É uma prática que subleva o sujeito e o menospreza em relação ao objeto: a experiência ergue-se como senhora das respostas. Pouco importa quem é o sujeito, ele muito provavelmente apenas emprestará seu nome, que ficará talvez como um gênio na historia, pois conseguiu "descobrir" ciência. Nesse caso importaria distinguir sujeitos masculino e feminino?

Ao provocar um retorno ao empirismo, as empiristas ingênuas parecem desprezar a tradição de um feminismo que busca recuperar o papel da mulher na sociedade, em busca de igualdade entre os sujeitos, preservando suas diferenças, e considerando história, cultura e aspectos sociais e políticos, o que o método científico simplesmente não vai levar

10 HARDING, S. Whose Science Whose Knowledge? Thinking from Women's Lives. Ithaca: Cornell University Press, 1991.

11 Idem, p. 111-118.

12 CEREZO, J. A. L. et al. “¿Qué es la ciencia? In Ciencia, Tecnologia y Sociedad: una aproximación conceptual. Cuadernos de Iberoamerica. Madrid: OEI, 2001. 
em conta. Ao contrário, repele esses aspectos e abraça a ciência para que avance linear e cumulativamente.

As empiristas ingênuas e sua prática de querer a 'boa ciência' situamse no campo de fazer e justificar os resultados. Seus trabalhos têm origem nas pesquisas sobre a possibilidade de uma ciência feminista em biologia. Trata-se, na opinião de Harding, de relevar muito mais as "virtudes científicas convencionais" - adotando um discurso de objetividade e verdade "antigas e fortes" - do que propriamente levar em conta o movimento feminista de uma maneira geral.

Outra epistemologia cotejada como feminista é a denominada enfoque psicodinâmico. Seu objetivo é explorar as conseqüências de a ciência ter sido construída - majoritariamente por homens a partir de estudos sobre as diferenças entre raciocínio ou moralidade entre homens e mulheres e a teoria psicoanalítica $^{13}$. Nessa linha, autoras como Evelyn Fox Keller defendem que homens e mulheres são diferentes porque foram submetidos a diferentes processos de aprendizagem emocional desde o nascimento. Assim, meninos dominam e meninas aprendem a integrar. Aplicando essa lógica na ciência, se constataria que ela foi produzida por homens e, conseqüentemente, resultou numa objetividade estática, cuja meta é o controle da natureza ${ }^{14}$. Fosse feita por mulheres, essa mesma ciência adotaria uma noção dinâmica de objetividade, uma imagem mais complexa e interativa do mundo.

Fox Keller, por exemplo, defende em Reflections on Gender and Science a idéia de objetividade dinâmica, a partir da junção de amor, força e conhecimento $^{15}$. A pesquisadora também escreveu uma biografia da bióloga Bárbara McClintock ${ }^{16}$, que ganhou o Prêmio Nobel, em 1983, por seu trabalho sobre a genética do milho. Ao escrever a biografia de McClintock, Fox Keller, também bióloga, parece querer comprovar a existência de uma objetividade dinâmica e um fazer feminino de ciência.

13 GONZÁLES GARCÍA, M., PERES SEDEÑO, E. op. cit., p. 13.

14 Ibidem.

15 KELLER, E F. Reflections on Gender and Science. New Haven/ London: Yale University Press, 1985.

16 KELLER, E. F. op. cit. 
Ao fazer tal distinção entre sujeitos masculino e feminino, o enfoque psicodinâmico corre o risco de cair no essencialismo. Não é à toa que logo ao início de Reflections on Science Gender, Fox Keller dedica boas páginas para discutir "Amor e Sexo na Epistemologia Platônica" na perspectiva das ligações históricas entre mente e natureza. De certa forma, ao questionar o amor e o sexo na filosofia platônica, Fox Keller já nos introduz num mundo de opostos. É como se dissesse que na essência mulheres e homens são diferentes e o produto dos seus fazeres científicos e tecnológicos também o serão. O essencialismo não resolve o problema pensar/ sentir, razão/ emoção, pelo contrário, assevera-o.

O essencialismo, na opinião de Peres Sedeño e Gonzáles García, também é o perigo da teoria feminista do ponto de vista, cuja autora mais conhecida é Sandra Harding. A teoria feminista do ponto de vista é de origem marxista e adota o reconhecimento do caráter socialmente situado das crenças. Às mulheres é dado um privilégio epistemológico de ver coisas que aos homens não seria possível, pois o seu território é o do poder.

Harding $^{17}$ justifica sua argumentação de uma ciência feminista, perpassando questões como: (1) a vida das mulheres, como diferente da dos homens, tendo sido erroneamente desvalorizada e negligenciada como ponto de partida para a pesquisa científica como geradora de evidência para ou contra o direito do conhecimento; (2) as mulheres são preciosas "estrangeiras" na ordem social, o que as leva a serem discriminadas e excluídas nos projetos e na direção da ordem social e da produção do conhecimento; (3) tornar-ganhar uma consciência feminista é um processo doloroso para muitas mulheres; (4) as mulheres estão do outro lado da batalha diária, construindo suas histórias resistindo à opressão; (5) a perspectiva das mulheres é a do dia-a-dia, entre outras.

Harding opõe a noção tradicional de objetividade, que julga parcial, ao que denomina objetividade forte, a qual é proporcionada pelo ponto de vista feminista ${ }^{18}$.

Levando-se em conta, como analisam Pérez Sedeño e Gonzáles García, que há várias experiências femininas e pontos de vista, seria difícil

17 Harding. op. cit., p. 121-133.

18 Idem, p. 138-163. 
definir qual dos pontos de vista seria o mais privilegiado. Ao perigo do essencialismo, acrescento o do relativismo.

A dificuldade de se discernir o conhecimento científico como privilegiado em relação a outros ou a consideração apenas dos aspectos sociais, desenlaçados do conteúdo empírico, pode levar a ciência a assumir mesmo patamar de práticas pseudocientíficas e mesmo status de outros tipos de conhecimento.

Menciono ainda outras duas epistemologias, os empirimos feministas contextuais e as pós-modernas. No primeiro caso, assume-se que o sujeito do conhecimento é o indivíduo, seguindo uma estratégias de lhes multiplicar. Ou seja, considerar como sujeito a própria comunidade científica. Talvez o problema, aqui, seja como definir essas comunidades e como elas entram em consenso sobre a validade de teorias.

As epistemologias pós-modernas, por sua vez, concebem ciência como "narrar histórias", uma negociação de interesses, não de busca da verdade. Há um problema de possibilidade do conhecimento que talvez não se resolva. Literatura, etnografia, jornalismo também narram histórias e se situariam, segundo a perspectiva pós-moderna, no mesmo plano da ciência. É a epistemologia feminista relativista por excelência. Ergue-se aqui uma série de aspectos a serem rebatidos, os quais certamente abordarei em outro trabalho.

As epistemologias acima apresentadas também se aplicam ao conhecimento tecnológico, embora este, com suas especificidades, tenha criado espaços que pesquisam questões como a influência do desenvolvimento tecnológico na liberação e na opressão da mulher (tecnootimismo), o caráter patricarcal da tecnologia (tecno-pessimismo), a aproximação das mulheres à natureza, construção cultural da tecnologia como masculina (enfoques sociohistóricos), até mesmo a neutralidade da tecnologia (feminismo liberal).

\section{(RE) DEFININDO A OBJETIVIDADE CIENTÍFICA: TENTATIVAS}

Quais as implicações de se considerar o gênero na ciência e na tecnologia? Qual a objetividade possível considerando-se o gênero? 
Inicialmente, é importante que se tenha em conta a dificuldade de se definir ciência e tecnologia. Na definição tradicional, em que a ciência é vista como um empreendimento autônomo, neutro e objetivo não se discutem as relações entre ciência e poder. Isso implicaria em considerar o sujeito em seus contextos histórico, social, cultural, ideológico. Mas ser autônoma, neutra e objetiva significa o ser em relação ao sujeito, arrancado de qualquer compromisso moral, social cultural, histórico e político. $\mathrm{O}$ que desejo desenvolver a seguir é que a introdução da categoria gênero para se discutir a origem e o desenvolvimento da ciência pode contribuir para que não se alheie da construção do conhecimento o sujeito feminino historicamente inferiorizado e dicotomizado em relação ao masculino - rumo a uma ciência e tecnologia humanistas. Cabe lembrar o "privilégio" e o "castigo" do demiurgo platônico mencionado ao princípio deste trabalho.

A noção tradicional de objetividade a distingue como propriedade independente dos seres humanos e seus contextos. Nesse caso, ela é uma espécie de produto final de um processo onde o conhecimento produzido opõe-se às responsabilidades, moral e social do cientista ${ }^{19}$. A objetividade aqui é confundida com passividade política e ética, argüindo-se uma pretensa neutralidade, que colabora com o desenvolvimento de um conhecimento linear, longe das crises, das remodelações profundas ${ }^{20}$.

Tomas Kuhn, em Estrutura das Revoluções Científicas, discute um desenvolvimento da ciência que passa por estágios de revoluções que a transformam.

(...) consideramos revoluções científicas aqueles episódios de desenvolvimento não-cumulativo, os quais um paradigma mais antigo é total ou parcialmente substituído por um novo, incompatível com o anterior. ${ }^{21}$

O paradigma "revela um conjunto de ilustrações recorrentes e quase padronizadas de diferentes teorias nas suas aplicações conceituais,

19 PERES SEDEÑO, E. "La Perspectiva del género en ciencia y tecnología: innovación y nueva caracterización de las disciplinas”. In: Ciencia, Tecnología, Sociedad y Cultura en el Cambio de Siglo. Madrid: Biblioteca Nueva, 2001, p. 291.

20 CEREZO. op. cit.

21 KUHN, T. op. cit., p. 145. 
instrumentais e na observação"22. Quando um determinado paradigma não é mais bem sucedido na busca pela verdade e na resolução de problemas, surgem anomalias, que por sua vez geram crises. Um novo paradigma poderá resolver a crise. Kuhn compara o processo de aceitação de um novo paradigma ao da revolução política.

As revoluções políticas visam realizar mudanças nas instituições políticas, mudanças essas proibidas por essas mesmas instituições que se quer mudar. Conseqüentemente, seu êxito requer o abandono parcial de um conjunto de instituições em favor de outro. ${ }^{23}$

Essa mudança leva os cientistas a verem o mundo de uma maneira diferente. É algo que envolve as comunidades das quais eles fazem parte, sem desprezar seus compromissos de pesquisa, seu tempo, sua situação de sujeito historicamente construído. Investigando a história, Tomas Kuhn teorizou sobre o desenvolvimento da ciência. Assim, o sujeito neutro que protagonizou a ciência do empirismo lógico despe-se e se revela indivíduo histórico.

Assim também ocorre nas comunidades tecnológicas, resguardadas as peculiaridades entre o conhecimento científico e o tecnológico, suas práticas e filosofias, e a ação deste último na direção do estado da arte, da necessidade, concepção, viabilidade e produção $0^{24}$.

(...) é bem possível que significativos contingentes humanos estejam sob os efeitos de um autêntico "sonambulismo tecnológico", que os faz seguir nadando ao sabor das correntezas, quando não simplesmente observando passivamente barcos singrando as águas, sem ao menos discernir os destinos a que estes movimentos poderão levá-los". ${ }^{25}$

22 Idem, p. 67.

23 Idem, p. 67.

24 BAZZO, W. A., PEREIRA, L.T.V. “Projeto”, In Introdução à Engenharia.Florianópolis: EDUFSC, 1996, p.76.

25 BAZZO, W. A. Educação Tecnológica - enfoques para o ensino de engenharia. Florianópolis:

EDUFSC, 2000, p. 142. 
O sonambulismo tecnológico, entre outros pontos, precisa ser refletido na educação tecnológica: "Viver só de projetar e construir, ou só de pensar e criticar, é viver pela metade" ${ }^{26}$.

O que penso aqui é experimentar uma análise que aproxime a ciência e a tecnologia de uma prática que pode ser feminista. As mulheres fizeram e fazem ciência e tecnologia, mas suas histórias foram relegadas a um plano secundário. Recuperar a história e o fazer científico e tecnológico dessas mulheres esquecidas, (re) contando a história, é um dos resultados dos trabalhos que incluem a categoria gênero em análises da história da ciência e da tecnologia.

O caráter histórico nos faz mudar o foco para discutir a noção de objetividade, deslocando-o irremediavelmente para fora da dicotomia pensar/ sentir, razão/ emoção. A objetividade seria alcançada também pelo consenso de uma comunidade científica.

O sujeito feminino também é histórico, com a diferença de que foi construído a partir de condicionantes diferentes da do sujeito masculino. Não podemos dizer que à mulher cabe mais subjetividade que ao homem; e a este último caberia a objetividade. Seríamos no mínimo essencialistas. Mas o problema é que historicamente os sujeitos masculino e feminino foram construídos em oposição. E as relações de poder estão aí imbricadas.

Abandonar a oposição pensar/ sentir, razão/ emoção é crer que o "modelo de ciência que manejam muitos cientistas e a filosofia da ciência da concepção herdada não é neutra" 27 .

(...) como todo modelo surge de uma tradição e está impregnada de seus valores. E um modelo que se denomina masculino porque se associa a características masculinas e as potencializa, pois suprime aquelas associadas ao feminino. ${ }^{28}$

Concordamos com Pérez Sedeño quando questiona se foram excluídos os fatores subjetivos do processo de laboração/ construção/ obtenção do

27 PERES SEDEÑO. op. cit., p. 293.

28 Ibidem. 
conhecimento científico e tecnológico. E cabe perguntar: quem é o sujeito cognoscente e o objeto conhecido, então?

Se não temos mais um sujeito cognoscente neutro, pois abandonamos a noção tradicional de objetividade científica, estamos em busca de um novo sujeito, que mantém seus laços históricos, culturais, sociais e políticos. Nesse caso, ciência não se opõe a poder, mas com ele interage - e vice-versa.

As epistemologias feministas, como vimos parágrafos atrás, com os devidos reparos e alguma exceção, enxergam esse novo sujeito cognoscente como "participativo, envolvido emocionalmente e comprometido com o que faz" ${ }^{29}$.

O conhecimento exige aprendizagem constante, interpretação em vários níveis, em diversos graus, em suma, algo muito mais completo do que o esquema $S$ sabe que $P$ ". ${ }^{30}$

Podemos falar agora então no sujeito feminino como um sujeito situado no conhecimento. Isso significa que o conhecimento está condicionado pelo sujeito e sua situação particular. Assim, como discute Gonzáles García ${ }^{31}$, os padrões de justifcativa dependerão das condições nas quais aparece e se desenvolve.

Ocontexto de descobrimento se torna relevante para o contexto de justificação, e noções como conhecimento, justificativa, objetividade... se revolucionam e se transformam. ${ }^{32}$

Cabem, então, não mais um ponto de vista apenas na elaboração de sistemas de conhecimento, o que se pode aproveitar para dizer que não há um método científico apenas, mas vários métodos, abertos também à criatividade dos cientistas, reunidos em comunidade, com regras, valores e objetivos nem sempre comuns.

29 Ibidem.

30 CODE apud PERES SEDEÑO, op. cit., p. 293-294.

31 GONZÁLES GARCÍA, “Género y Conocimiento”, in CEREZO, op. cit., p. 351.

32 Idem. 
Desejo refletir a construção do conhecimento como uma prática social também. Para Helen Longino ${ }^{33}$, é possível adotar um raciocínio construtivo de duas formas, através dos valores individuais ou dos valores da comunidade científica. Quer dizer que os argumentos que são usados a favor de determinadas evidências dependem do seu contexto; certos dados constituem evidência, ao contrário de outros, favoráveis a determinadas hipóteses no embate com outras hipóteses ou pressupostos básicos. Nota-se, então, que a objetividade da qual estamos falando enlaça a crítica social com a evidência empírica.

Eu quero crer também, como Donna Haraway ${ }^{34}$, que as feministas não necessitam de reeditar a objetividade em termos de transcendência, perdendo "o rastro de suas mediações justamente quando alguém deva ser responsabilizado por algo, e poder instrumental ilimitado”.

Gostaria de uma doutrina de objetividade corporificada que acomodasse os projetos científicos feministas críticos e paradoxais: objetividade feminista significa, simplesmente, saberes localizados. [...] apenas a perspectiva parcial promete uma visão objetiva ${ }^{35}$.

Isso quer dizer que um valor como o da responsabilidade não pode ser relegado a uma esfera extracientífica. Dinâmica, a perspectiva parcial abarca as responsabilidades pelas "promessas" e "monstros destrutivos. É uma leitura da objetividade que a limita a um determinado espaço (mas, na verdade, a amplia) e localiza historicamente o conhecimento construído pelas mulheres, sem divisar relações entre sujeito e objeto do conhecimento, destruindo potencialmente dicotomias que alimentam relações desiguais de poder.

A perspectiva parcial concebe e concede olhares privilegiados, porém a mirada não é "inocente".

Elas são preferidas porque, em princípio, são as que têm menor probabilidade de permitir a negação do núcleo crítico e interpretativo de todo o conhecimento. Elas têm ampla

33 LONGINO, Helen. Science as Social Knowledge - values and objectivity in scientific inquiry. New Jersey: Princenton University Press, 1990. p. 81-82.

34 HARAWAY, D. "Saberes localizados: a questão da ciência para o feminismo e o privilégio da perspectiva parcial”. In: Cadernos Pagu. n.5, 1995, p. 16.

35 Idem, p. 18; p. 21. 
experiência com os modos de negação através da repressão, do esquecimento e dos atos de desaparição - com maneiras de não estar em nenhum lugar ao mesmo tempo em que se alega tudo ver. [...] As perspectivas dos subjugados são preferidas porque parecem prometer explicações mais adequadas, firmes, objetivas, transformadoras do mundo. ${ }^{36}$

Um outro ponto nessa discussão (que gostaríamos de aprofundar n'outro momento) é de que conferimos aos sujeitos uma dinâmica, geralmente negada aos objetos do conhecimento. Um olhar mais atento, um saber localizado, vai tratar de enxergar um objeto mutante, que age, no tempo e no espaço, que também é passível de transformação. É preciso que se abandone a noção de uma lógica da descoberta ${ }^{37}$ e se construa mais firmemente a idéia de que 0 conhecimento se produz nas inter-relações de poder entre sujeito e objeto.

\section{RECONTAR TIMEO VAMOS FALAR DE EDUCAÇÃO?}

Se consideramos o conhecimento como uma soma de prática social e conteúdo empírico tenho que (re) contar o "privilégio" e o "castigo" das almas do Timeo. Tanto mulheres, quanto homens poderiam deslindar seus passos nos caminhos da razão e da emoção, sem que isso se constituísse numa atitude a ser menosprezada. Se consideramos a educação como uma prática voltada à autonomia do indivíduo, temos, mais que nunca, que considerar o sujeito feminino como constituinte dessa prática e seu lugar na possibilidade, na origem e na essência do conhecimento. Autonomia, aqui, não significa neutralidade.

Em tempo algum pude ser um observador "acinzentadamente" imparcial, o que porém, jamais me afastou de uma posição rigorosamente ética. (...) Significa reconhecer que a História é tempo de possibilidade e não de determinismo, que o futuro, permita-se-me reiterar, é problemático e não inexorável”38.

36 Idem, p. 23.

37 Idem, p. 37.

38 FREIRE, Paulo. Pedagogia da Autonomia - saberes necessários à prática educativa, São Paulo: Paz e Terra, 2002. p. 15, 21. 
Se consideramos essa objetividade na ciência e na tecnologia, não esbarramos na discriminação. Se discriminamos, recriminamos o gênero, trocamos a autonomia do sujeito pela autonomia da ciência. Mas se adotamos a primeira, mulheres e homens serão estrelas, sem privilégios ou castigos na "reencarnação". Reveladas e resguardadas as suas diferenças históricas, talvez brilhem mais.

\section{REFERÊNCIAS}

BAZZO, W. A. Educação tecnológica - enfoques para o ensino de engenharia. Florianópolis: EDUFSC, 2000.

BAZZO, W. A., PEREIRA, L.T.V. Projeto. In: Introdução à Engenharia. Florianópolis: EDUFSC, 1996.

CEREZO, J. A. L. et al. ¿Qué es la ciencia? In: Ciencia, Tecnología y Sociedad: una aproximación conceptual. Madrid: OEI, 2001. (Cuadernos de Iberoamerica)

CITELI, M.T. Mulheres nas ciências: mapeando campos de estudo. In: LOPES, Maria Margaret (Org.) Cadernos pagu: gênero, ciência, história. Campinas: Unicamp, 2000.

FREIRE, Paulo. Pedagogia da autonomia - saberes necessários à prática educativa. São Paulo: Paz e Terra, 2002.

GONZÁLES GARCÍA, M. Género y conocimiento. In: CEREZO, J. A. L.; RON, J. M. S. Ciencia, tecnología, sociedad y cultura en el cambio de siglo. Madrid: Biblioteca Nueva, 2001.

GONZÁLES GARCÍA, M.; PÉREZ SEDEÑO, E. Ciencia, tecnología y gênero. Revista iberoamericana de ciência, tecnología, sociedad y innovación, Madrid, n. 2, enero - abr. 2002. 
HARAWAY, D. Saberes localizados: a questão da ciência para o feminino e o privilégio da perspectiva parcial. Cadernos Pagu, n.5, 1995.

HARDING, S. Whose science whose knowledge? Thinking from women's lives. Ithaca: Cornell Unversity Press, 1991.

KELLER, E F. Reflections on gender and science. New Haven/ London: Yale University Press, 1985.

KOCHEN, Silvia, FRANCHI, Ana, MAFFÍA, Diana, ATRIO, Jorge. Situación de las mujeres en el sector científico-tecnológico en América Latina. In: PÉREZ SEDEÑO, E. (Editora) Las mujeres en el sistema de ciencia y tecnología: estudios de caso. Madrid: OEI, 2001, p. 19-39. (Cuadernos de Iberoamerica)

KUHN, T. A estrutura das revoluções científicas. São Paulo: Perspectiva, 2000.

LONGINO, Helen. Science as social knowledge - values and objectivity in scientific inquiry. New Jersey: Princenton University Press, 1990.

LOPES, M. M. Gênero, Ciências, História. Revista do Núcleo de Estudos de Gênero Pagu. UNICAMP, 2000.

PÉREZ SEDEÑO, E. La perspectiva del género en ciencia y tecnología: innovación y nueva caracterización de las disciplinas. In: CEREZO, J. A. L., RON, J. M. S. Ciencia, tecnología, sociedad y cultura en el cambio de siglo. Madrid: Biblioteca Nueva, 2001.

SHIEBINGER, L. O feminismo mudou a ciência? São Paulo: Universidade do Sagrado Coração, 2001.

VIEJA, M. T. L.. (Ed.) Feminismo: del pasado al presente. Salamanca: Universidad de Salamaca, 2000. 
